\title{
Five Decades of Enucleations for Uveal Melanoma in One Center: More Tumors with High Risk Factors, No Improvement in Survival over Time
}

\author{
Christine D.M. Roelofsen ${ }^{a, b} \quad$ Annemijn P.A. Wierenga ${ }^{a} \quad$ Sjoerd van Duinen ${ }^{c}$ \\ Robert M. Verdijkc, d Jaco Bleeker ${ }^{a}$ Marina Marinkovic ${ }^{a} \quad$ Gregorius P.M. Luyten $^{a}$ \\ Martine J. Jager ${ }^{\mathrm{a}}$ \\ a Department of Ophthalmology, Leiden University Medical Center, Leiden, The Netherlands; \\ ${ }^{b}$ Department of Emergency Medicine, Leiden University Medical Center, Leiden, The Netherlands; \\ 'Department of Pathology, Leiden University Medical Center, Leiden, The Netherlands; \\ ${ }^{\mathrm{d}}$ Department of Pathology, Section Ophthalmic Pathology, Erasmus MC University Medical Center \\ Rotterdam, The Netherlands
}

\section{Keywords}

Eye diseases · Ocular oncology · Uveal melanoma ·

Epidemiology · Survival

\begin{abstract}
Background: In order to improve medical care for uveal melanoma (UM) patients, we need to monitor disease and survival to guide our research efforts. We analyzed the data of UM patients who underwent an enucleation at the Leiden University Medical Center over the last five decades and investigated trends in patient and tumor characteristics and survival. Methods: Data were collected from charts and pathology reports from all patients who underwent an enucleation for UM between 1973 and 2019 ( $n=1,212)$, of which 1,066 were primary enucleations; data were analyzed according to five time periods: 1973-1979 ( $n=209), 1980-1989$ ( $n=148), 1990-1999$ ( $n=174), 2000-2009$ ( $n=280)$, and 2010-2019 ( $n=401)$. Results: Over time, mean patient age at the time of enucleation for UM increased from 54.9 to 64.7 years ( $p<0.001$ ), more tumors showed histopathological involvement of the ciliary body $(p<0.001)$, and were classified in a high TNM/AJCC class
\end{abstract}

karger@karger.com www.karger.com/oop

Karger $\frac{1}{\%}$

GOPEN ACCESS
(C) 2020 The Author(s)

Published by S. Karger AG, Basel

This is an Open Access article licensed under the Creative Commons Attribution-NonCommercial-4.0 International License (CC BY-NC) (http://www.karger.com/Services/OpenAccessLicense), applicable to the online version of the article only. Usage and distribution for commercial purposes requires written permission. $(p<0.001)$. Overall, the 5- and 10-year UM-related survival rates were 0.68 and 0.59 , respectively. Over time, survival showed no change in patients with tumors in AJCC stages I or III, with recently a slightly worse survival in stage II UM $(p=0.02)$. Conclusion: Between 1973 and 2019, we found similar rates of UMrelated survival following enucleation, although we noticed a strong increase in more unfavorable patient and tumor characteristics over time, such as an older age and larger tumor size. The lack of improvement indicates that more research should take place to develop adjuvant treatments to prevent metastases and efficient treatments once metastases develop.

(C) 2020 The Author(s)

Published by S. Karger AG, Basel

\section{Introduction}

Uveal melanoma (UM) is a rare tumor, even though it is the most common primary intraocular malignancy in adults. It originates from melanocytes in the uvea and

Christine D.M. Roelofsen and Annemijn P.A. Wierenga contributed equally. 
mainly affects Caucasians, with an incidence of 5-7 per million in Western countries [1-5]. The mean age at diagnosis is around 60 years $[3,4,6]$. In most studies, women and men are affected equally, although some have reported a slightly higher incidence in males $[3,4]$.

The 5-year survival rate of UM ranges from 60 to $82 \%$ [7-11], and the 10-year rate from 40 to $87 \%[7,9,11-$ 13]. Most deaths are attributed to UM metastases [12, $14,15]$, which involve the liver in $90 \%$ of cases $[16,17]$. The mean time from primary tumor treatment to metastatic disease is 5.5 years [17], but metastases may develop even 40 years after the initial diagnosis $[18,19]$. With respect to the effectiveness of modern treatments, UM differs greatly from cutaneous melanoma as immunotherapy and mutation-targeting therapies are mostly ineffective in UM [20,21]. Immunotherapy [22, 23] and treatment of liver metastases by isolated liver perfusion may prolong life in specific cases [24]. After detection of UM metastases, $80 \%$ of patients die within 1 year $[16,17$, 25].

Many different clinical and pathological UM parameters are associated with the development of metastases and poor prognosis. These include older age at presentation, a high largest basal diameter of the tumor, a high percentage of epithelioid cells, high mitotic activity, ciliary body involvement, extraocular extension, and the presence of an inflammatory phenotype [6, 26-29]. The TNM (Tumor Node Metastasis) staging classification by the American Joint Committee on Cancer (AJCC) combines tumor size, ciliary body involvement, and extraocular extension to classify patients into prognostic groups, with higher classes being associated with increased mortality [30]. Genetic factors for a poor prognosis include monosomy 3 (M3) and 8q amplification, a Class 2 gene expression profile, and loss of BRCA1-associated protein-1 (BAP1) expression [31-35].

With the development of sophisticated local treatments such as radioactive plaques and proton beam irradiation, enucleation has become a last resort approach. Furthermore, more intense follow-up and the introduction of new approaches, such as immunotherapy, isolated liver perfusion or resection and targeted chemotherapy, might have led to better survival. Our study population, which includes patients treated at the Leiden University Medical Center (LUMC) over the past 46 years, provides a large cohort, allowing the analysis of trends over time. The objective of this study is to determine whether, during this time period, changes occurred in tumor characteristics of patients selected to undergo enucleation and whether survival improved.

\section{Methods}

\section{Study Population}

Data were collected from all patients who underwent an enucleation for UM at the LUMC, The Netherlands, between 1973 and $2019(n=1,212)$. The LUMC has been the main treatment center for UM in The Netherlands for over 50 years, and a standardized database for enucleations was set up in 1973. Data were analyzed based on five time periods, corresponding to five different decades: 1973-1979 ( $n=209), 1980-1989$ ( $\mathrm{n}=148), 1990-1999(n=174)$, 2000-2009 $(n=280)$, and 2010-2019 $(n=401)$. The variables assessed in this study include characteristics of the patients, histopathological tumor characteristics, chromosome status, and data on survival and the presence of metastatic disease.

\section{Patient and Histopathological Characteristics}

Both clinical information, such as age at enucleation, gender, affected eye, and ocular treatment prior to enucleation, and data on histopathological characteristics were collected from patient charts. Histopathological characteristics were determined through routine conventional analysis by ophthalmic pathologists. These included tumor location, involvement of the ciliary body, tumor thickness, largest basal diameter, and cell type. Tumors were staged in accordance with the 8th edition of the AJCC Cancer Staging Manual, using the TNM model for anatomical staging [30, 36].

\section{Chromosome Status}

Analysis of chromosome status of UM started at our institution in 1999. Chromosome 3 status was obtained in 487 patients. This was tested by karyotyping, fluorescence in situ hybridization (FISH), or single nucleotide polymorphism (SNP) array, as previously described [37, 38]. In short, karyotyping was performed following the regulations of the International System for Human Cytogenetic Nomenclature (1995), FISH was performed with DNA probes specific for the centromere of chromosome 3, and SNP array was performed with extracted DNA using the Affymetrix 250K_NSP microarray (Affymetrix, Santa Clara, CA, USA). When any of these tests revealed monosomy 3 , the tumor was categorized as such $[34,39-41]$.

\section{Survival}

Data about survival were obtained using both data from patients' charts and data retrieved from the Dutch National Cancer Registry. Follow-up time was last updated in August 2019 and was defined as the time between enucleation and death or last date of follow-up. The numbers of patients lost to follow-up were: 18 in total; 2 from 1973 to 1979; 4 from 1980 to 1989; 1 from 1990 to 1999; 8 from 2000 to 2009; 3 from 2010 to 2019.

\section{Statistical Analysis}

Data were analyzed retrospectively using IBM SPSS Statistics version 25. Associations between categorical variables were assessed using linear-by-linear association. Numerical variables were compared between the 5 groups using the one-way ANOVA test. Survival analyses were performed using Kaplan-Meier curves and compared with a log-rank test in SPSS. Additionally, multivariate binary logistic regression analysis and Cox univariate analysis were performed to examine time as a predictor of survival. Differences were considered statistically significant with $p<0.05$. 
Table 1. Clinical and histopathological variables of UM cases that underwent enucleation, divided over five decades

\begin{tabular}{|c|c|c|c|c|c|c|c|}
\hline Gender $(n=1,212)$ & & & & & & & $0.13^{\mathrm{a}}$ \\
\hline Male & $662(55)$ & $109(52)$ & $76(51)$ & $94(54)$ & $151(54)$ & $232(60)$ & \\
\hline Eye $(n=1,212)$ & & & & & & & $0.31^{\mathrm{a}}$ \\
\hline Right eye & $610(50)$ & $107(51)$ & $63(43)$ & $88(51)$ & $141(50)$ & $211(50)$ & \\
\hline Primary therapy $(n=1,212)$ & & & & & & & $<0.001^{\mathrm{a}}$ \\
\hline Primary enucleation & $1,066(88)$ & $209(100)$ & $141(95)$ & $148(85)$ & $222(79)$ & $346(86)$ & \\
\hline Transpupillary thermotherapy & $11(1)$ & $0(0)$ & $0(0)$ & $2(1)$ & $9(3)$ & $0(0)$ & \\
\hline Ruthenium brachytherapy & $61(5)$ & $0(0)$ & $4(3)$ & $6(3)$ & $15(5)$ & $36(9)$ & \\
\hline Sandwich therapy & $42(3.5)$ & $0(0)$ & $0(0)$ & $13(7.5)$ & $25(9)$ & $4(1)$ & \\
\hline Proton beam therapy & $26(2)$ & $0(0)$ & $3(2)$ & $5(3)$ & $8(3)$ & $10(2.5)$ & \\
\hline Mid choroid & $740(61)$ & $162(78)$ & $90(61)$ & $84(48)$ & $198(68)$ & $215(54)$ & $<0.001^{\mathrm{a}}$ \\
\hline Posterior pole & $499(41)$ & $102(49)$ & $43(36)$ & $75(43)$ & $120(43)$ & $149(37)$ & $0.05^{\mathrm{a}}$ \\
\hline Tumor diameter $(n=1,192), \mathrm{mm}$ & $11.3 \pm 3.7$ & $10.9 \pm 3.7$ & $11.4 \pm 3.1$ & $10.6 \pm 3.6$ & $12.0 \pm 3.9$ & $11.3 \pm 3.8$ & $0.001^{\mathrm{b}}$ \\
\hline Tumor thickness $(n=1,192), \mathrm{mm}$ & $5.7 \pm 3.6$ & $5.1 \pm 3.3$ & $5.4 \pm 3.1$ & $5.1 \pm 3.1$ & $6.4 \pm 3.3$ & $6.0 \pm 3.3$ & $<0.001^{\mathrm{b}}$ \\
\hline Cell type $(n=1,194)$ & & & & & & & $<0.001^{\mathrm{a}}$ \\
\hline Spindle & $353(31)$ & $109(52)$ & $44(30)$ & $69(40)$ & $86(31)$ & $75(18)$ & \\
\hline Epithelioid or mixed & $811(68)$ & $97(46)$ & $101(68)$ & $98(56)$ & $192(69)$ & $323(82)$ & \\
\hline Tumor pigmentation $(n=1,170)$ & & & & & & & $0.27^{\mathrm{a}}$ \\
\hline None to mild & $617(53)$ & $117(57)$ & $67(48)$ & $89(52)$ & $158(60)$ & $186(47)$ & \\
\hline Moderate to heavy & $553(47)$ & $90(43)$ & $74(52)$ & $81(48)$ & $103(40)$ & $205(52)$ & \\
\hline Scleral ingrowth $(n=1,197)$ & & & & & & & $<0.31^{\mathrm{a}}$ \\
\hline None to superficial & $770(64)$ & $129(62)$ & $79(53)$ & $121(70)$ & $164(59)$ & $277(70)$ & \\
\hline Deep & $281(24)$ & $57(28)$ & $49(33)$ & $34(20)$ & $81(29)$ & $60(15)$ & \\
\hline IIIC & $15(1)$ & $2(1)$ & $2(1)$ & $1(0.6)$ & $7(3)$ & $3(1)$ & \\
\hline IV & $2(0.2)$ & $0(0)$ & $1(0)$ & $0(0)$ & $0(0)$ & $2(1)$ & \\
\hline Monosomy $3(n=487)$ & & & & & & & $0.12^{\mathrm{a}}$ \\
\hline No & $230(47)$ & ND & ND & $2(50)$ & $80(47)$ & $148(47)$ & \\
\hline Yes & $257(53)$ & ND & ND & $2(50)$ & $89(53)$ & $166(53)$ & \\
\hline
\end{tabular}

Variables are denoted as $n(\%)$ or the mean $\pm \mathrm{SD}$. ND, not determined.

Group differences were tested with: ${ }^{a}$ linear-by-linear association; ${ }^{b}$ one-way ANOVA.

\section{Results}

A total of 1,212 patients underwent enucleation for UM at the LUMC in Leiden between 1973 and August 2019 , of which 1,066 were primary enucleations. Table 1 displays the main variables of the study cohort, compared between the 5 time periods.

Uveal Melanoma over Time

\section{Clinical Features}

From 1973 and 2019, the age at enucleation rose considerably, with a significant difference of 9.8 years in mean age between the first and last time period $(p<$ 0.001 ). No significant changes were observed in gender distribution over the years, with an overall percentage of $55 \%$ males. The number of enucleations peaked in the last 
Fig. 1. Different therapies of eyes undergoing enucleation for UM between 1973 and 2019, displayed as the absolute number of patients in each time period.

Fig. 2. TNM stage of UM in enucleated eyes between 1973 and 2019.
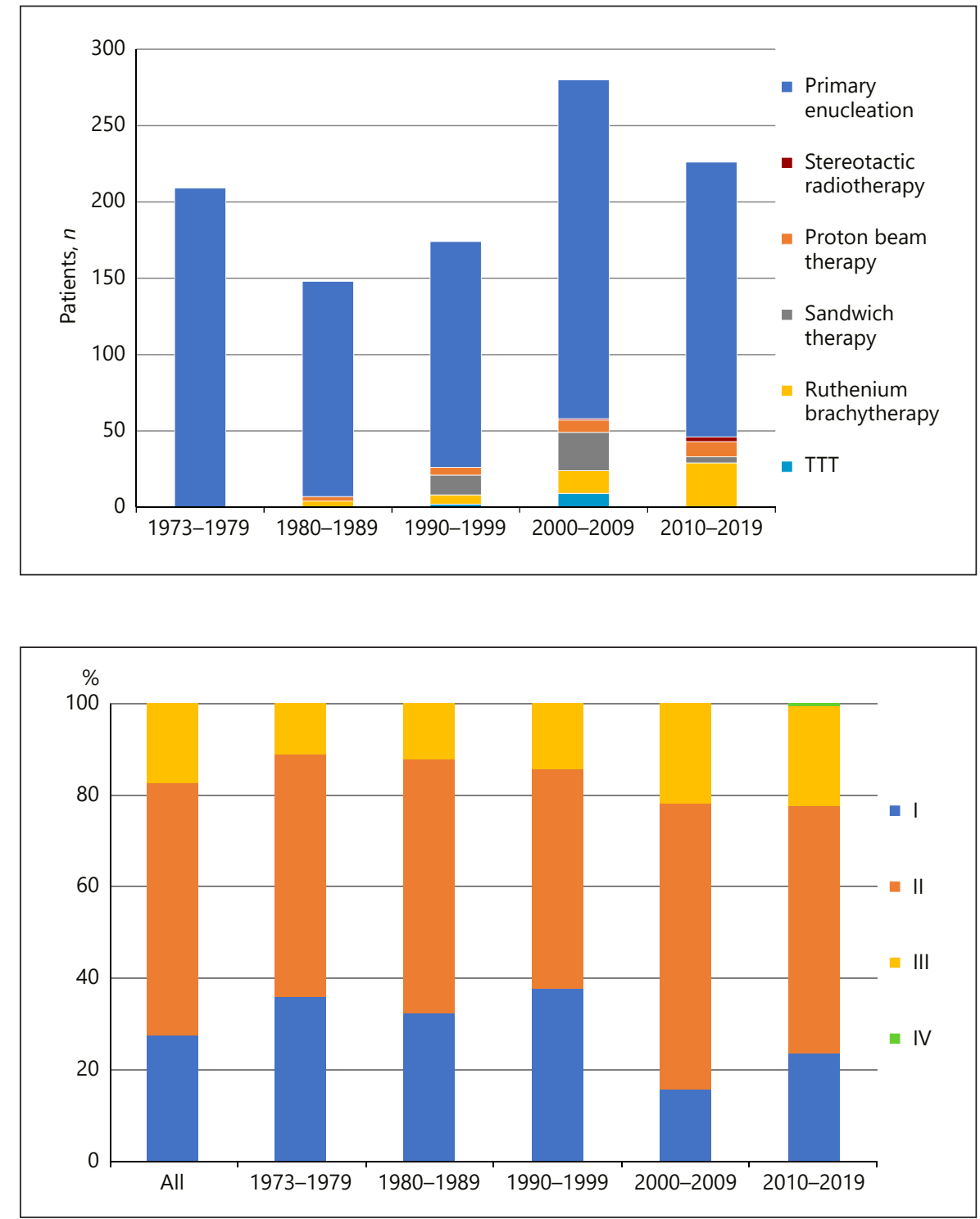

2 decades. Among all time periods, enucleations were predominantly primary enucleations; however, the type of therapy given prior to secondary enucleations differed significantly between the groups. Enucleations following transpupillary thermotherapy (TTT) and sandwich therapy (a combination of ruthenium brachytherapy and TTT) were especially noticed in 3 and $9 \%$ of the cases, respectively, in the 2 time periods between 1990 and 2010, when this therapy was en vogue (Fig. 1) [42].

\section{Histopathology}

Tumor location changed over the years, mainly due to a significant increase in involvement of the ciliary body and peripheral choroid while the number of tumors with mid-choroidal (the area between the vascular arcade and peripheral choroid), and posterior pole involvement remained stable. Both tumor thickness and diameter increased in the last 2 time periods. Regarding the AJCC stage of the patients, in the first 3 time periods over $30 \%$ of tumors were stage I, but this was $<25 \%$ in the last 2 , while stage II fluctuated around $50 \%$ and TNM stage III increased steadily over time from 11 to $25 \%(p<0.001$; Fig. 2).

In $1973-1979,52 \%$ of the tumors showed a spindle cell type and $48 \%$ a mixed or epithelioid cell type. However, by $2010-2019$, this had changed to $18 \%$ spindle cell versus $82 \%$ mixed or epithelioid $(p<0.001)$. Tumor pigmentation and (extra)scleral tumor extension showed some 
Table 2. UM-related and overall survival in patients who underwent enucleation for UM, divided according to decade

\begin{tabular}{lllllll}
\hline & $\begin{array}{l}\text { All } \\
(n=1,209)\end{array}$ & $\begin{array}{l}1973-1979 \\
(n=208)\end{array}$ & $\begin{array}{l}1980-1989 \\
(n=147)\end{array}$ & $\begin{array}{l}1990-1999 \\
(n=173)\end{array}$ & $\begin{array}{l}2000-2009 \\
(n=280)\end{array}$ \\
\hline $\begin{array}{l}\text { 5-year UM-related survival } \\
\text { 10-year UM-related survival }\end{array}$ & $\begin{array}{l}0.68(0.66-0.70) \\
0.59(0.55-0.63)\end{array}$ & $\begin{array}{l}0.77(0.71-0.83) \\
0.70(0.64-0.76)\end{array}$ & $\begin{array}{l}0.63(0.55-0.71) \\
0.55(0.47-0.63)\end{array}$ & $\begin{array}{l}0.76(0.70-0.82) \\
0.64(0.56-0.72)\end{array}$ & $\begin{array}{l}0.66(0.60-0.72) \\
0.56(0.50-0.63)\end{array}$ & $\begin{array}{l}0.60(0.52-0.68) \\
\text { ND }\end{array}$ \\
\hline $\begin{array}{l}\text { 5-year overall survival } \\
\text { 10-year overall survival }\end{array}$ & $0.59(0.55-0.63)$ & $0.69(0.63-0.75)$ & $0.58(0.50-0.66)$ & $0.64(0.56-0.72)$ & $0.58(0.52-0.64)$ & $0.49(0.43-0.55)$ \\
\hline
\end{tabular}

Data are presented as the proportion $(95 \% \mathrm{CI})$. ND, not determined (value could not yet be calculated at the time of the study).

fluctuations between the groups, but the differences were not statistically significant. The chromosome status was mainly known in 2000-2009 and 2010-2019. In both time periods the percentage of tested patients with monosomy 3 was $53 \%$.

\section{Survival}

UM-related survival Kaplan-Meier curves differed significantly between the time periods; however, no specific trend or pattern could be identified (log-rank test $p=0.001$ ). Table 2 displays UM-related survival and overall survival proportions in all groups. Combining all cases, UM-related survival was 0.68 after 5 years and 0.59 after 10 years. The 5- and 10-year UM-related survival rates were, respectively, 0.77 and 0.70 in 1973-1990, 0.63 and 0.55 in 1980-1989, 0.76 and 0.64 in 1990-1999, and 0.66 and 0.56 in 2000-2009, with a 5-year survival for 2010-2019 of 0.60 . However, comparing the first and last UM-related survival curve within the different AJCC stages, the survival did not significantly change in stage I $(p=0.37)$ and stage III $(p=0.64)$, but did in stage II ( $p=$ 0.02 ), where a worse survival was seen for the most recent time period (Fig. 3). A multivariate analysis with time periods as a predictor of mortality was performed, correcting for age at enucleation and AJCC stage. The adjusted odds ratios with the period 1973-1979 as the reference were 0.70 (95\% CI 0.45-1.10) for $1980-1989,1.01$ (95\% CI 0.65-1.57) for 1990-1999, 1.01 (95\% CI 0.731.61) for 2000-2009, and 2.38 (95\% CI 1.94-3.57) for 2010-2019.

\section{Discussion}

When comparing five decades of our cohort of 1,212 UM patients who underwent enucleation at the LUMC between 1973 and 2019, we found no improvement in UM-related survival over time after correction for the
TNM/AJCC stage. Stage II even showed a slightly worse 5 -year survival during the last decade than during the first period. Also, the adjusted odds ratio for mortality was the highest in the period between 2000 and 2019 . We noticed changes over time regarding tumor characteristics, including an increase in age, an increased involvement of the tumor in the ciliary body, and a higher prevalence of AJCC stage III at the expense of AJCC stage I.

Even though, in general, the treatment for UM has changed from enucleation to eye-preserving treatments, and new approaches have become available to treat metastases (for example, hepatic perfusion, liver surgery, chemotherapy, and immunotherapy), we did not see an improvement in survival over time. When looking at the tumor characteristics, we observed a shift to higher risk categories (AJCC stage, ciliary body involvement). This means that the included cases in our cohort have, over time, changed to more patients with more aggressive tumors. We think this trend is the result of the selection of cases that require enucleation, as this has now become the treatment of last resort in often elderly patients who cannot be treated by radioactive plaque or proton beam therapy: the significant increment of age at enucleation over the years may be due to alternative treatments being offered to younger, more resilient individuals, leaving the older patients in the study cohort. The fact that not only tumor TNM/AJCC stage but also other parameters such as age play a role is demonstrated by the decreased UM-related survival in the last decade compared to the first for AJCC stage II.

A few studies have investigated UM mortality over time. Aronow et al. [5] compared 5-year relative survival rates in a cohort of 4,999 patients, in 3-year time intervals from 1973 to 2013, which remained stable around $81 \%$ over time. Bergman et al. [43] calculated a crude survival rate of $60 \%$ at 5 years and $43 \%$ at 10 years, and a relative survival of $70 \%$ at 5 years and $59 \%$ at 10 


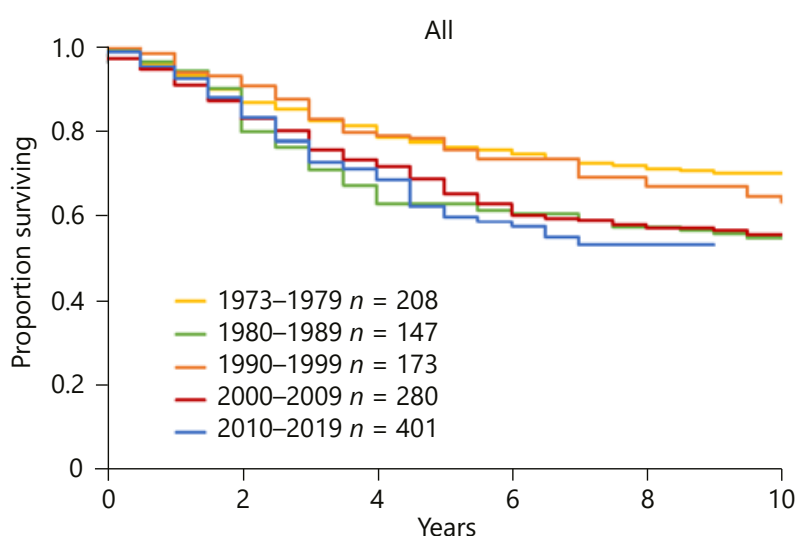

At risk

$\begin{array}{cccccc}1973-1979 & 178 & 157 & 142 & 125 & 117 \\ 1980-1989 & 127 & 91 & 82 & 69 & 64 \\ 1990-1999 & 150 & 122 & 106 & 96 & 86 \\ 2000-2009 & 233 & 187 & 148 & 108 & 65 \\ 2010-2019 & 251 & 127 & 55 & 18 & \end{array}$

a 2010-2019 251

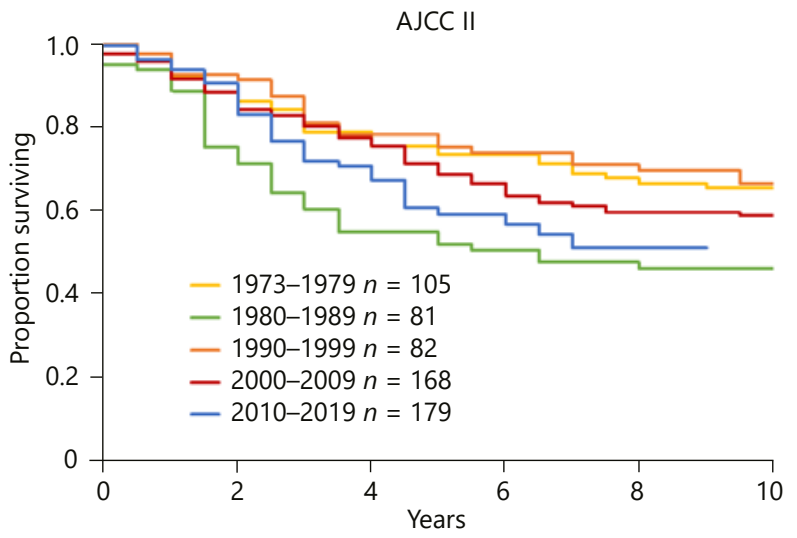

At risk

$\begin{array}{cccccc}1973-1979 & 87 & 75 & 68 & 58 & 53 \\ 1980-1989 & 67 & 44 & 37 & 30 & 29 \\ 1990-1999 & 72 & 58 & 52 & 48 & 44 \\ 2000-2009 & 142 & 118 & 91 & 76 & 60 \\ 2010-2019 & 112 & 66 & 28 & 10 & \end{array}$

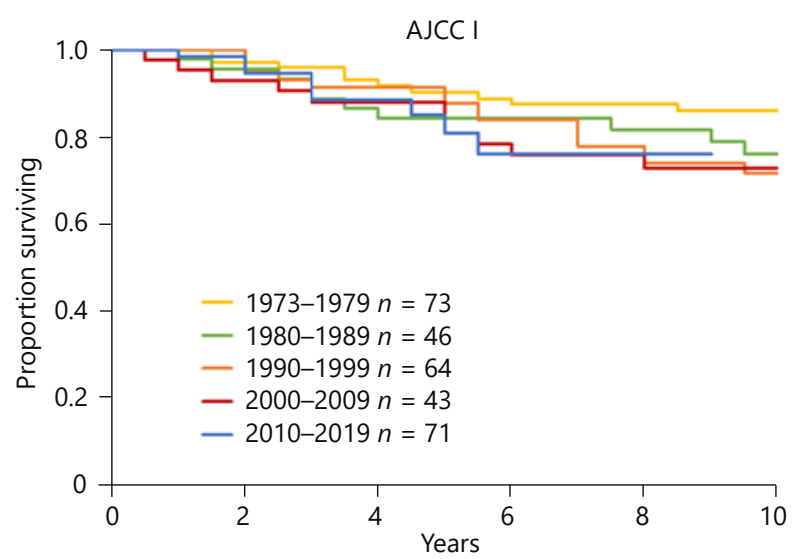

At risk

$\begin{array}{cccccc}1973-1979 & 70 & 67 & 62 & 57 & 54 \\ 1980-1989 & 44 & 37 & 36 & 31 & 28 \\ 1990-1999 & 58 & 52 & 44 & 39 & 33 \\ 2000-2009 & 39 & 36 & 31 & 27 & 21 \\ 2010-2019 & 54 & 33 & 15 & 6 & \end{array}$

AJCC III

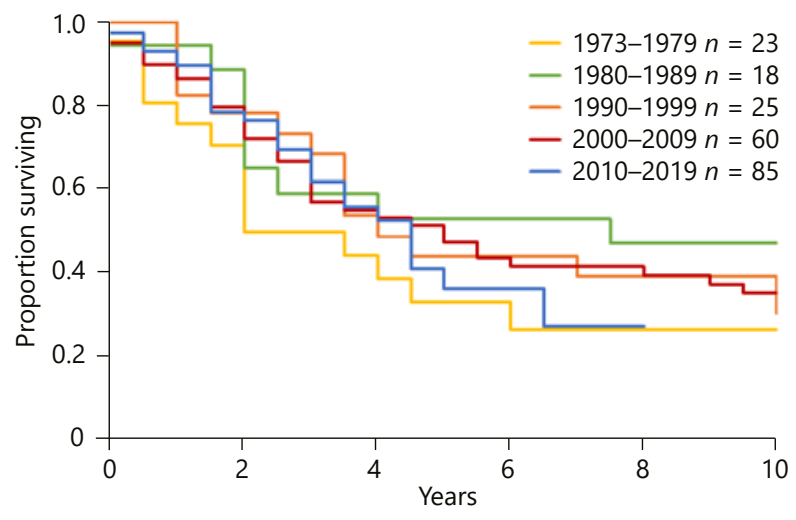

At risk

$\begin{array}{cccccc}1973-1979 & 14 & 8 & 5 & 4 & 4 \\ 1980-1989 & 15 & 10 & 9 & 8 & 7 \\ 1990-1999 & 18 & 11 & 9 & 8 & 8 \\ 2000-2009 & 44 & 29 & 22 & 20 & 15 \\ 2010-2019 & 40 & 19 & 7 & 1 & \end{array}$

Fig. 3. Kaplan-Meier curves showing UM-related survival of patients who underwent an enucleation for UM in 5 different time groups, respectively, for all patients $(p<0.001 ; \mathbf{a})$, AJCC stage I $(p=0.37 ; \mathbf{b})$, AJCC stage II $(p=$ $0.02 ; \mathbf{c})$, and AJCC stage III $(p=0.64 ; \mathbf{d})$.

years, from 2,997 cases with UM between 1960 and 1998. Kujala et al. [8] investigated the very long-term prognosis of UM in Finland and found a 5-year melanoma-related mortality of $31 \%$, and a 35 -year rate of $52 \%$. They followed a cohort of 289 patients included between 1962 and 1981 but did not compare their data to a more recent cohort. Their report does not state if the frequency of poor prognostic histopathological factors increased or decreased over time. Other investigations on UM-related survival only report average survival rates without comparison between cohorts from varying time periods. Our 5- and 10-year UM-related mortalities are comparable to the rates in the other mentioned studies [7-11, 27]. However, reports differ and depend on the type of primary UM that are included (for example, primary tumor size and location). Therefore, to observe trends in 
survival, it must be measured in cohorts that are comparable regarding epidemiological factors. A study by Shao et al. [44] reviewed 49 studies to investigate the reasons for different survival outcomes in UM patients with a bad prognosis. They concluded that both study methods and outcome methods have to be standardized in order to generate comparable survival data [44]. By and large, our findings are consistent with the limited available data regarding UM survival trends over time.

A recent paper concerning metastatic UM stated that different treatment modalities of metastases have not made a difference to mortality $[45,46]$. In the Netherlands a registry has been set up that includes UM patients with metastases. Jochems et al. [47] studied this cohort, consisting of 227 patients that were included between 2012 and 2018; 175 of these patients provided complete data. Cases that were eligible for local treatment of metastases (for example, surgical resection, isolated hepatic perfusion with melphalan, radiotherapy, radiofrequency ablation) showed the best survival, with a 1 -year survival of $82 \%$, versus $49 \%$ for systemic therapy and $28 \%$ for supportive care. These data indicate that especially young patients with a good WHO performance score and few metastatic sites are good candidates for local therapy. Although we do not know how many of the patients in their study [47] were included in our cohort, it is likely that there is overlap.

This investigation has several limitations. First, we only had access to the data of enucleated patients. We think that the cases that were included in our analysis typically concern the larger and more aggressive tumors. In the most recent decades, smaller tumors did not require enucleation and were consequently poorly represented in our cohort. Our results are therefore more reliable for larger than smaller tumors. Another limitation is that, while some advocate the use of time to metastases as a measure of tumor malignancy, we did not have reliable data on the onset of metastatic disease.

However, over the last five decades, we noticed that enucleation takes place in older patients with more highrisk tumor characteristics, as patients with low-risk tumors are eligible for treatments other than enucleation. Despite the development of more specialized treatment of primary tumors, our results do not show improvement in survival rates, but the increased age of the groups (from a mean of 54.9 to 64.7 years) may play a role here. When using the risk assessment algorithm LUMPO III [48], this becomes obvious: when assessing the survival of a male patient with a UM with a largest basal diameter of $15 \mathrm{~mm}$, thickness of $5 \mathrm{~mm}$, and monosomy 3, 10-year survival in a 54 -year old would be predicted to be $47 \%$, but in a 64 -year old would be $35 \%$. The focus of engagement in UM research should be on adjuvant treatment to prevent metastases and treatment of metastatic disease. The results of treating metastatic UM with combinations of immune checkpoint inhibitors and the application of new therapies such as tebentafusp (formerly IMCgp 100) are eagerly awaited, generating potential for the future $[22,23,49,50]$.

Additionally, for future studies investigating UM survival trends, we recommend studying all UM patients, not only those who underwent enucleation. To monitor disease, evaluate treatment and survival, and guide our research efforts into the right direction, it is very important to conduct epidemiological studies on UM patient groups.

\section{Statement of Ethics}

This research was conducted ethically in accordance with the World Medical Association Declaration of Helsinki. The project was approved in August 2019 by the Biobank and Medical Ethics Committee of the LUMC (No. Uveamelanoomlab-2019-9/METC B19.049). The research adhered to Dutch law and the tenets of the Declaration of Helsinki (World Medical Association of Declaration 2013; ethical principles for medical research involving human subjects). According to Dutch rules and guidelines on medical research, patients' written permission for the use of pathological specimens for research was not needed.

\section{Conflict of Interest Statement}

The authors have no conflicts of interest to declare.

\section{Funding Sources}

This research was funded by the European Commission through Horizon 2020 grant No. 667787, UM CURE 2020 (APAW).

\section{Author Contributions}

C.D.M.R., A.P.A.W., and M.J.J. designed and conducted the study, including analysis and interpretation of the data and manuscript preparation. S.v.D., R.M.J., J.B., M.M. and G.P.M.L. were involved in data collection and manuscript review. 


\section{References}

1 Isager P, Østerlind A, Engholm G, Heegaard $\mathrm{S}$, Lindegaard J, Overgaard J, et al. Uveal and conjunctival malignant melanoma in Denmark, 1943-97: incidence and validation study. Ophthalmic Epidemiol. 2005 Aug; 12(4):223-32.

2 McLaughlin CC, Wu XC, Jemal A, Martin HJ, Roche LM, Chen VW. Incidence of noncutaneous melanomas in the U.S. Cancer. 2005 Mar;103(5):1000-7.

3 Singh AD, Turell ME, Topham AK. Uveal melanoma: trends in incidence, treatment, and survival. Ophthalmology. 2011 Sep; 118(9):1881-5.

4 Mahendraraj K, Lau CS, Lee I, Chamberlain RS. Trends in incidence, survival, and management of uveal melanoma: a populationbased study of 7,516 patients from the Surveillance, Epidemiology, and End Results database (1973-2012). Clin Ophthalmol. 2016 Oct;10:2113-9.

5 Aronow ME, Topham AK, Singh AD. Uveal Melanoma: 5-Year Update on Incidence, Treatment, and Survival (SEER 1973-2013). Ocul Oncol Pathol. 2018 Apr;4(3):145-51.

6 Shields CL, Furuta M, Thangappan A, Nagori S, Mashayekhi A, Lally DR, et al. Metastasis of uveal melanoma millimeter-by-millimeter in 8033 consecutive eyes. Arch Ophthalmol. 2009 Aug;127(8):989-98.

7 Diener-West M, Earle JD, Fine SL, Hawkins BS, Moy CS, Reynolds SM, et al.; Collaborative Ocular Melanoma Study Group. The COMS randomized trial of iodine 125 brachytherapy for choroidal melanoma, III: initial mortality findings. COMS Report No. 18. Arch Ophthalmol. 2001 Jul;119(7):969-82.

8 Kujala E, Mäkitie T, Kivelä T. Very long-term prognosis of patients with malignant uveal melanoma. Invest Ophthalmol Vis Sci. 2003 Nov;44(11):4651-9.

9 Burr JM, Mitry E, Rachet B, Coleman MP. Survival from uveal melanoma in England and Wales 1986 to 2001. Ophthalmic Epidemiol. 2007 Jan-Feb;14(1):3-8.

10 Jovanovic P, Mihajlovic M, Djordjevic-Jocic J, Vlajkovic S, Cekic S, Stefanovic V. Ocular melanoma: an overview of the current status. Int J Clin Exp Pathol. 2013 Jun;6(7):1230-44.

11 Kroll S, Char DH, Quivey J, Castro J. A comparison of cause-specific melanoma mortality and all-cause mortality in survival analyses after radiation treatment for uveal melanoma. Ophthalmology. 1998 Nov;105(11):2035-45.

12 Pereira PR, Odashiro AN, Lim LA, Miyamoto C, Blanco PL, Odashiro M, et al. Current and emerging treatment options for uveal melanoma. Clin Ophthalmol. 2013;7:1669-82.

13 Chew AL, Spilsbury K, Isaacs TW. Survival from uveal melanoma in Western Australia 1981-2005. Clin Exp Ophthalmol. 2015 Jul; 43(5):422-8.
14 Kivelä T, Kujala E. Long-term Risk of Melanoma-Related Mortality After Uveal Melanoma. JAMA Ophthalmol. 2016 Feb;134(2): 238-9.

15 Woodman SE. Metastatic uveal melanoma: biology and emerging treatments. Cancer J. 2012 Mar-Apr;18(2): 148-52.

16 Diener-West M, Reynolds SM, Agugliaro DJ, Caldwell R, Cumming K, Earle JD, et al.; Collaborative Ocular Melanoma Study Group. Development of metastatic disease after enrollment in the COMS trials for treatment of choroidal melanoma: Collaborative Ocular Melanoma Study Group Report No. 26. Arch Ophthalmol. 2005 Dec;123(12):1639-43.

17 Nicholas MN, Khoja L, Atenafu EG, Hogg D, Quirt I, Butler M, et al. Prognostic factors for first-line therapy and overall survival of metastatic uveal melanoma: The Princess Margaret Cancer Centre experience. Melanoma Res. 2018 Dec;28(6):571-7.

18 Shields JA, Augsburger JJ, Donoso LA, Bernardino VB Jr, Portenar M. Hepatic metastasis and orbital recurrence of uveal melanoma after 42 years. Am J Ophthalmol. 1985 Nov; 100(5):666-8

19 Coupland SE, Sidiki S, Clark BJ, McClaren K, Kyle P, Lee WR. Metastatic choroidal melanoma to the contralateral orbit 40 years after enucleation. Arch Ophthalmol. 1996 Jun; 114(6):751-6.

20 Rodrigues M, Koning L, Coupland SE, Jochemsen AG, Marais R, Stern MH, et al.; UM Cure 2020 Consortium. So Close, yet so Far: Discrepancies between Uveal and Other Melanomas. A Position Paper from UM Cure 2020. Cancers. 2019 Jul;11(7):E1032.

21 van der Kooij MK, Speetjens FM, van der Burg SH, Kapiteijn E. Uveal Versus Cutaneous Melanoma; Same Origin, Very Distinct Tumor Types. Cancers. 2019 Jun;11(6):E845.

22 Wierenga AP, Cao J, Luyten GP, Jager MJ. Immune Checkpoint Inhibitors in Uveal and Conjunctival Melanoma. Int Ophthalmol Clin. 2019;59(2):53-63.

23 Rodrigues M, Mobuchon L, Houy A, Fiévet A, Gardrat S, Barnhill RL, et al. Outlier response to anti-PD1 in uveal melanoma reveals germline MBD4 mutations in hypermutated tumors. Nat Commun. 2018 May;9(1):1866.

24 de Leede EM, Burgmans MC, Kapiteijn E, Luyten GP, Jager MJ, Tijl FG, et al. Isolated (hypoxic) hepatic perfusion with high-dose chemotherapy in patients with unresectable liver metastases of uveal melanoma: results from two experienced centres. Melanoma Res. 2016 Dec;26(6):588-94.

25 Augsburger JJ, Corrêa ZM, Shaikh AH. Effectiveness of treatments for metastatic uveal melanoma. Am J Ophthalmol. 2009 Jul; 148(1):119-27.

26 Shammas HF, Blodi FC. Prognostic factors in choroidal and ciliary body melanomas. Arch Ophthalmol. 1977 Jan;95(1):63-9.
27 Hawkins BS; Collaborative Ocular Melanoma Study Group. The Collaborative Ocular Melanoma Study (COMS) randomized trial of preenucleation radiation of large choroidal melanoma: IV. Ten-year mortality findings and prognostic factors. COMS report number 24 . Am J Ophthalmol. 2004 Dec;138(6):936-51.

28 Nayman T, Bostan C, Logan P, Burnier MN Jr. Uveal Melanoma Risk Factors: A Systematic Review of Meta-Analyses. Curr Eye Res. 2017 Aug;42(8):1085-93.

29 Bronkhorst IH, Jager MJ. Inflammation in uveal melanoma. Eye. 2013 Feb;27(2):217-23.

30 Amin MB, Greene FL, Edge SB, Compton CC, Gershenwald JE, Brookland RK, et al. The Eighth Edition AJCC Cancer Staging Manual: Continuing to build a bridge from a population-based to a more "personalized" approach to cancer staging. CA Cancer J Clin. 2017 Mar;67(2):93-9.

31 van Essen TH, van Pelt SI, Versluis M, Bronkhorst IH, van Duinen SG, Marinkovic M, et al. Prognostic parameters in uveal melanoma and their association with BAP1 expression. Br J Ophthalmol. 2014 Dec;98(12):1738-43.

32 Koopmans AE, Verdijk RM, Brouwer RW, van den Bosch TP, van den Berg MM, Vaarwater J, et al. Clinical significance of immunohistochemistry for detection of BAP1 mutations in uveal melanoma. Mod Pathol. 2014 Oct;27(10):1321-30.

33 Harbour JW, Onken MD, Roberson ED, Duan S, Cao L, Worley LA, et al. Frequent mutation of BAP1 in metastasizing uveal melanomas. Science. 2010 Dec;330(6009):14103.

34 Onken MD, Worley LA, Ehlers JP, Harbour JW. Gene expression profiling in uveal melanoma reveals two molecular classes and predicts metastatic death. Cancer Res. 2004 Oct; 64(20):7205-9.

35 Dogrusöz M, Jager MJ. Genetic prognostication in uveal melanoma. Acta Ophthalmol. 2018 Jun;96(4):331-47.

36 Al-Jamal RT, Cassoux N, Desjardins L, Damato B, Konstantinidis L, Coupland SE, et al. The Pediatric Choroidal and Ciliary Body Melanoma Study: A Survey by the European Ophthalmic Oncology Group. Ophthalmology. 2016 Apr;123(4):898-907.

37 Dogrusöz M, Kroes WG, van Duinen SG, Creutzberg CL, Versluis M, Bleeker JC, et al. Radiation Treatment Affects Chromosome Testing in Uveal Melanoma. Invest Ophthalmol Vis Sci. 2015 Sep;56(10):5956-64.

38 Dogrusöz M, Ruschel Trasel A, Cao J, Çolak S, van Pelt SI, Kroes WG, et al. Differential Expression of DNA Repair Genes in Prognostically-Favorable versus Unfavorable Uveal Melanoma. Cancers. 2019 Aug;11(8):E1104.

Roelofsen et al. 
39 Dogrusöz M, Jager MJ, Damato B. Uveal Melanoma Treatment and Prognostication. Asia Pac J Ophthalmol. 2017 Mar-Apr;6(2):186-96.

40 Gezgin G, Dogrusöz M, van Essen TH, Kroes WG, Luyten GP, van der Velden PA, et al. Genetic evolution of uveal melanoma guides the development of an inflammatory microenvironment. Cancer Immunol Immunother. 2017 Jul;66(7):903-12.

41 Maat W, Ly LV, Jordanova ES, de WolffRouendaal D, Schalij-Delfos NE, Jager MJ. Monosomy of chromosome 3 and an inflammatory phenotype occur together in uveal melanoma. Invest Ophthalmol Vis Sci. 2008 Feb;49(2):505-10.

42 Tjho-Heslinga RE, Davelaar J, Kemme HM, de Vroome H, Oosterhuis JA, Bleeker JC, et al. Results of ruthenium irradiation of uveal melanomas: the Dutch experience. Radiother Oncol. 1999 Nov;53(2):133-7.
43 Bergman L, Seregard S, Nilsson B, Lundell G, Ringborg U, Ragnarsson-Olding B. Uveal melanoma survival in Sweden from 1960 to 1998. Invest Ophthalmol Vis Sci. 2003 Aug; 44(8):3282-7.

44 Shao YF, Echegaray JJ, Singh N, Singh AD. Variability of Bad Prognosis in Uveal Melanoma. Ophthalmol Retina. 2019 Feb;3(2): $186-93$.

45 Lorenzo D, Piulats JM, Ochoa M, Arias L, Gutiérrez C, Català J, et al. Clinical predictors of survival in metastatic uveal melanoma. Jpn J Ophthalmol. 2019 Mar;63(2):197-209.

46 Rantala ES, Hernberg M, Kivelä TT. Overall survival after treatment for metastatic uveal melanoma: a systematic review and meta-analysis. Melanoma Res. 2019 Dec;29(6):561-8
47 Jochems A, van der Kooij MK, Fiocco M, Schouwenburg MG, Aarts MJ, van Akkooi AC, et al. Metastatic Uveal Melanoma: Treatment Strategies and Survival-Results from the Dutch Melanoma Treatment Registry. Cancers. 2019 Jul;11(7):E1007.

48 Eleuteri A, Taktak AF, Coupland SE, Heimann H, Kalirai H, Damato B. Prognostication of metastatic death in uveal melanoma patients: A Markov multi-state model. Comput Biol Med. 2018 Nov;102:151-6.

49 Damato BE, Dukes J, Goodall H, Carvajal RD. Tebentafusp: $\mathrm{T}$ cell redirection for the treatment of metastatic uveal melanoma. Cancers. 2019 Jul;11(7):E971.

50 Jager MJ, Shields CL, Cebulla CM, AbdelRahman M, Grossniklaus H, Stern MH, et al. Uveal Melanoma. Nat Rev Dis Primers. 2020;6(1):24. 